\title{
A Sociolinguistic Study of Linguistic Taboos in Send My Roots Rain by Ibis Gomes Vega
}

\author{
Muhammad Shaffaqat ${ }^{1}$ Q (D) , Madam Nadia Bi Bi ${ }^{2}$ \& (D), Muhammad Ali Shahid ${ }^{3}$ (D) $\triangle$ and Farooq \\ Ahmad48 (iD) \\ ${ }^{1}$ Scholar, the University of Lahore, Sargodha Campus, Pakistan \\ ${ }^{2}$ Lecturer, the University of Lahore, Sargodha Campus, Pakistan \\ ${ }^{3}$ Principal, the Hope College of Science \& Management Sillanwali, Pakistan \\ ${ }^{4}$ Scholar, the University of Lahore, Sargodha Campus, Pakistan
}

Corresponding Author: Muhammad Ali Shahid, E-mail: muhammadalishahid05@gmail.com

\section{ARTICLE INFORMATION}

Received: March 02, 2021

Accepted: April 22, 2021

Volume: 3

Issue: 4

DOI: $10.32996 /$ jeltal.2021.3.4.6

\section{KEYWORDS}

Sociolinguistic Study, Linguistic Taboos, Batistella's Theory of Bad Language, and Ibis Gomez Vega's Send My Roots Rain

\section{ABSTRACT}

A few issues are acknowledged and admitted for every public, while others are not considered appropriate at any point verbally expressed on open occasions. When used in correspondence, taboo words are appropriately interpreted as silly, appalling, or revolting. These are the words "limitations." The current study looks into all of the notable collections of English Linguistic taboos, such as genuine releases, end and illness, sex, four-letter words, security, and harsh language, which are independently described and given strong models. To deal with the conditions, abnormal and indirect strategies for avoiding using unapproachable words are proposed. Being a sociolinguistic report, the current research thesis aims to research the Linguistic Taboos in the novel "Send My Roots Rain" by Ibis Gomez Vega. The focal point of the novel is lesbianism. The protagonist of the novel goes under the attack of the previously described subject. The topic of lesbianism was discussed where the Theory of Bad Language by Batistella was used as a hypothetical framework. A Library summary was used to collect secondary data. The study investigated the kinds of semantic constraints and profane and forbidden body movements that permeated in the novel in the novel. At any rate, these Linguistic Taboos are forbidden in public, but in the event that somebody like Carol, the hero of the novel, goes under an assault of the illicit and restricted crime, it is not just a Spanish individual's calamity; it can immerse various social orders moreover. As these kinds of limitations are once penetrated, none can stop and annihilate except drastic devastations. A pilot study was done for the data mining.

\section{Introduction}

This part depicts the foundation of the research. It also clarifies the research focus, research objectives, and the hypothetical and practical research significance. The term taboo is derived from Tongan, a Polynesian language, and refers to an illegal and forbidden act that is not acceptable in society. Societal norms do not allow such bad words. Body parts, significant limits, sexual development and practices, exacting, philosophical topics mentioned in Totem and Taboo are examples of socially illegal topics (Freud, 1955). A word implying one of the linguistic taboos is sometimes referred to as an unapproachable word/derivation nono/verbal no-no, as Hornby (2005) communicates that "Words that are consistently perceived as threatening, staggering, rude, for example, because they insinuate sex, a body organ, or race." Every society and dialect have no-no guidelines that serve as a control for the network when creating their correspondence. Nonetheless, norms are ignored in certain particular environments and reasons in cultural life. Individuals face difficulties when they violate no-no rules. In a partnership, words may be used to offend and harm the feelings of others. Those words are associated with disgusting and sensitive topics, such as sexual organs,

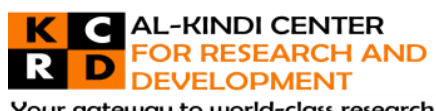

Your gateway to world-class research

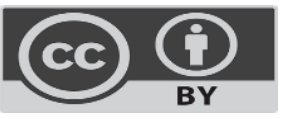

Published by Al-Kindi Center for Research and Development, United Kingdom. Copyright (c) the author(s). This open access article is distributed under a Creative Commons Attribution (CC-BY) 4.0 license 
sexual activity, soil, and so on, and are not considered reasonable for logical investigations. This suspicion may be justified at first, but from another perspective, such research is critical for providing social comprehension to the network about its reasons and objectives. From a social standpoint, it is necessary to include another aspect of human mind comprehension, as society is tested in their method of articulation by having forbiddances and social assents against such verbal articulations.

\subsection{Objectives of Study}

i. $\quad$ To find out Linguistic Taboos in "Send My Roots Rain" by Ibis Gomez Vega

ii. To explore the influence of Linguistic Taboos on Carol, the protagonist in "Send My Roots Rain" by Ibis Gomez Vega

iii. To highlight the effects of Linguistic Taboos on the Spanish society in "Send My Roots Rain" by lbis Gomez Vega

\subsection{Research Questions}

i. What types of Linguistic taboos were used in "Send My Roots Rain" by Ibis Gomez Vega?

ii. What was the influence of Linguistic Taboos on Carol, the protagonist in "Send My Roots Rain" by Ibis Gomez Vega?

iii. $\quad$ To what extent can the effects of Linguistic Taboos be highlighted on the Spanish society in "Send My Roots Rain" by Ibis Gomez Vega?

\section{Literature Review}

Walker (2015) conducts research on the topic "Accommodating Taboo Language in English Language Teaching: Issues of Appropriacy and Authenticity." He discusses the social language associated with relying on the consumer. In any case, when ordinary people use language with a taboo term, it is the responsibility of teachers to educate them about the inappropriate use of language and direct them in a better way to deal with it. It is forbidden to teach and learn a forbidden language. Dissatisfaction with sociolinguistic and social facts in the homeroom course there are unmistakably books to discuss excluded language, but what are the shortcomings they themselves have in looking out for such impediments and oversights? Uhlman (2015) ensures a comparative analysis of swears in school and the genuine social setting in his scholarly article "Use and Perception of Taboo Language in College-Age Female." He claims that the use of profanity in school is much more modest than in social settings. With the title "Schit Worde" meaning unfriend words, Richards (2015) went after linguistic taboos: "Analysis of Linguistic Taboos In the Presence of Semantic Field of Excrement." The combined study's aim was to investigate the use of censuring in the general population. The analysis of data shows the relationship between culture and language usage in the general population. It shows the manner in which the total population shifts, language changes and thus achieves semantic move enormousness and taboo statuses. Ahmad (2015) oversaw "The Influence of Social Taboos on Student Socialization: Evidence from a Developing Country." He ensures that in Pakistani schools, understudy endures a lot because of the unyielding concept of eh laws and rules concerning the organization. Furthermore, the general population's values motivate them to deal with the magnitude and coarseness of the laws. The evaluation study shows the terrible and negative impact of linguistic taboo on understudies' socialization. As a result, people are killed and become awful contracted or criminals. Anggita (2015) completed a proposal titled "A Sociolinguistic Analysis of Taboo Words in the Bad Teacher Film." The investigation study's focal point is to investigate linguistic taboos used by the character in the film. The film's topic suggests that the heinous instructor must achieve his goal by catching or breaking the law. The research looked into the different types and components of linguistic taboos enacted by the characters in the film. The findings of the investigation study indicate that linguistic taboos are present in the conversations of the speakers in the film. Sobriquet profanity, revoltingness, and flippancy are verbal taboos used in the trades. The character to convey and expose their disturbing power and discourteousness towards different characters in the film uses these terms.

Niraula (2016) led an evaluation study on the topic of "Linguistic Taboos and Euphemism in Nepali." 'This demonstrates that, while people are more conscious of avoiding the use of linguistic taboos, they purposefully use these terms with a slanderous sentiment of the cerebrum. In either case, the investigation included a corpus-based analysis of the threatening vocabulary. The expert's goal is to detect unpalatability in the language and provide an opportunity for language students to become acquainted with the language without the bad behaviour of euphemism." "Linguistic Taboos: A Case on Australian Lebanese Speakers," Fouad Abi-esber (2017) investigated. The thesis investigated the Lebanese way of life to correspond to the Australian context. The aim of combining the investigation study is to investigate how Lebanese Arabic speakers use English Taboo Word in their daily correspondence. The study's findings showed that the old Lebanese employ backhanded linguistic taboos.

On the other hand, Lebanese youth will generally use linguistic taboos separate from PC games. Jing-Schmidt (2019) wrote "a scholarly paper in which she investigated scolding, taboo, and code term." Referring to numerous scientists' theories, she claimed that these linguistic taboos had become a simple piece of everyday language that is as often as possible used by all 
language speakers. Linguistic taboos exist in every language on the planet. They can address various societies in any case; their lack of availability in any language is astounding. The degree of usage can differ from language to language, but they are available in every language and in every location on the planet." Kurniawati (2019) performs an investigation study and evaluates Taboo Words used by youths in the Stranger Things Season 2 TV plan. The study categorizes linguistic taboos into five categories: emotional, physical, challenging, and filthy. According to the findings of the evaluation report, the young characters usually use no-no terms to express their emotions rather than to offend their analysts. Besides, sexual terms and masterminds them subject to their capacities. In his insightful article "An Investigation into the Influence of Foreign Language Learning on the Use of Taboo Words in The Learners' First Language Discourse," Khaghaninejad (2020) examines the impact of obscure lingo on his public language, Persian. Throughout learning various types of taboo words examined by the expert. The study reveals how the path to learning new vernacular influences the first language, and the first language is changed by a similar number of words of the subsequent language blended in the first. This helps to understand why Arabic speakers use a more subdued version of the taboo word. In any case, no culture is capable of diverting taboo words. There may be variations, but taboo words can be found in every language on the planet.

\section{Theoretical Framework: Theory Of Bad Language By Batistella}

In this study, the researcher used qualitative methods to collect data from Ibis Gomez Vega's novel "Send My Roots Rain, 1991." The researcher used content analysis as a research tool in this report. The novel "Send My Roots Rain" by the author examined the widespread usage of taboo terms in Spanish culture. The taboo words were derived from the novel's material. The conversations of the novel's characters served as the content. Following Batistella's "Theory of Bad Language," the researcher investigated linguistic taboos in Ibis Gomez Veg's Send My Roots Rain. According to Batistella, forbidden terms fall into four categories: epithets, profanity, vulgarity, and obscenity. Via the characters' dialogue, the novel explores taboo words and movements. Phonetic Taboo refers to a term or a combination of words that refer to taboo topics.

\section{Data Analysis}

According to Batistella (2005), forbidden terms fall into four categories: epithets, profanity, vulgarity, and obscenity. The characters in the novel have used these forbidden words, which have a repulsive effect on the minds of the readers. The novel "Send My Roots Rain" by Ibis Gomez Vega gives the readers a sense of Spanish society's current state of affairs.

In the novel's plot, a metropolitan woman artisan appears at the invitation of the town minister in a small southwestern town near the Mexican border. She has come to paint wall paintings in his assemblage, oblivious to the devastating fire that has burned down the entire town and cruelly ended the life of her child. The professional worker turns into the driving force behind the town's appearance of its complete fault, allowing for the re-creation of the meeting and reconciliation between the Catholic cleric and the town's older person healer. Simultaneously, she confronts her horrific horrible visions, their source, and the goal of her sexual character.

Carol was a befuddled soul in the midst of the extreme heat of sandy spot Pozo Seco Society.

"I felt as if I were walking on air. A hot desert wind slapped my face with vengeance. The sand got into my mouth and wound its way through my hair like airy snakes. I felt the heat in the air, the stifling breath of sand, drawing the life out of me because I had dared come this far into its essence. The air turned red and I fell."

The preceding lines clearly and unmistakably show the extreme and brutal depiction of the sandy spot where she had stepped in and will certainly live for a reason to paint murals in a congregation, which is a blessed spot in a strict way. Because of the heat of the sun, she was drenched in sweat as she walked into the sandy area. She was going to die because of exhaustion. She was perplexed to the point where, in a state of embarrassment and in the midst of a tornado assault, she did not know whom to request that how Church where she intended to paint the wall paintings. She was alone and had no one to help her. She urgently requires the assistance of a guide. In that tense situation, she was looking for a ray of hope when a little nothing fiend named Zemi appeared out of nowhere.

From the start, the sight of the young lovely and impish girl is said to be a "Sustenance and Salwa" in the scorching desert. Carol let out a relieved sigh and hoped that Zemi would assuage her aches of difficulty and be her friend in need and guide later on. She was in desperate need of a person who could serve as her guide. This segment tends to warn the hero to brace himself for a difficult opportunity in the future. In any case, she was fully prepared to face all of the difficulties that awaited her; she was unaware of the foul and ludicrous existence of the citizens of Pozo Seco Society.

"She walked towards me with a confident smile on her face that told me she held the key to my bewilderment in the palm of her hand, and impish look of self-satisfaction that became her, like innocence, shone for her face. I was in trouble, and she came to rescue me". 
In the book, Zemi is a lovely girl who interacts with Carol. Carol had just arrived in town, and she was exhausted and on her way down the earth. She is Maria's daughter. Maria is a similar woman with whom Carol remains and later falls in love with and fulfils her sexual appetite by doing filthy and heinous things. It was assumed that Carol would be Maria's guest when Zemi interacted with her. Carol took a break while staying at Maria's house for an extended period. When she regained consciousness, she recalled her errand to paint the wall painting. She gathered her adornments and set out to find the congregation where she intended to carry out her responsibility, the practice of painting. When she was on her way to look for Father Arroyo's home, she was captured in the paws of the desert's burning heat. She could not conceal the gravity of the bad weather and collapsed on the beach.

"My clothes, drenched in sweat, clung to me as if a new layer of skin were tightening in on me".

She was half-dead, soaked in the preparing sand, when a man like "Manna in the bewilderment" suddenly appeared to shield her. He was described as a thoughtful and God-fearing person who protected and soothed her outburst of obviousness. He selected Carol from the consuming sand stove and relocated her. That person was a massive anonymous figure. Father Arroyo, the priest, was the one she intended to stay with and chip away at the wall paintings. Despite the fact that she was in a worried expression, she felt the dash of Father Arroyo's hands with an enticing psyche. She was standing next to herself when Father Arroyo approached her. She was unable to restrict and regulate her feelings and sexual desires. She felt adored in the delicate hands of a darling creation full of unbridled hot sentiment. She was ecstatic and knew she was going to succeed. The truth is that she was stimulated to sexual avarice while in Father Arroyo's arms. She needed to be desired in order to achieve the extraordinary. She was unable to control her vulgar desires and felt compelled to engage in sexual intercourse with Father Arroyo.

"I closed my eyes again, but the rising feelings stayed with me and I floated in her arms through space. To rising from the sand and feel the earth pull you back to its breast that must be life".

She seemed to be unconcerned about the severity of the weather, as she was dressed in a long-sleeved shirt in the sweltering heat. It was designed to be worn in cold weather. Carol could not stand the savage burring blistering climate of Pozo Seco. Maria drove Carol home. Carol arrived at home in an unstable state and had lost consciousness. She was half-dead on the beds. Her well-proportioned body was evident, and when the shirt catches open, the voluptuous young woman's bosom was going to be visible. Maria had put a high value on a bad brain for Carol. Carol was out of her mind, and she wanted to do something horrible to her. Carol could feel the sand going into her jeans, shirt, and even her hair when she regained consciousness and got up to change her dress. Maria became enraged at Carol as she was changing her filthy dress to alleviate her fear in order for her to return to consciousness and ordinary life.

"She undid most of buttons on woman's blouse, who wears a long sleeve into a desert?"

Maria was an extraordinarily kindhearted, co-usable woman, and God-dreading and God-fearing woman, and she was unrivalled in her willingness to aid and serve those she met in the hot waters. When she saw Carol had left in the sweltering heat, she became enthralled with the idea of pardoning her. Carol's outfit, which she felt was inappropriate for the hot weather, was quickly changed by her brain. She was doing her best to reassure Carol that she would return to life. She was treating and providing her with the best possible care in a professional manner. She had just stared at her luscious lips, very well developed and well-shaped sex hips, and curvaceous bare chest with a psyche of eagerness. She has definitely made Carol adjust her dress to smooth her, but during her administration that she was delivering for Carol, it was clear from her movements that she, too, had a homosexual inclination. She was hoping for a slanderous rabid opportunity to do terrible things to her the whole time.

"Removing the jeans embarrassed her. She felt a flash of something, some kind of emotion, and rush through her body, and she had to stand back to recover and reason through her embarrassment. Was she doing something wrong?

Carol was being undressed as her clothes were soiled with sand. She was snickering in herself as she removed her trousers because she was unable to restrict her own sexual attraction for her. She was so enthralled by the white and all around shaped fragile bums that she ran away in a state of hysteria. She needed to play with Carol's fragile bums, but she could not because Carol was not in her right mind. She took off her pants and replaced them with her own. Carol's main partner, Zemi, had a strong attraction to Caro as well. She was Maria's daughter. She felt an assault of jealousy when she saw Maria getting a charge out of the prey for which Zemi had fantasized. She could not stand seeing her mother's pants on anyone else. Indeed, she could not keep up under the dash of her mother's pants on Carol's delicate hips. She was staring at her white voluptuous bosom with profane eyes when changing her clothes. 


\section{"She found herself looking at woman's breast and then quickly buttoned the pajama to that was as Zemi predicted too short for her".}

Cora was Maria's best friend, and she was very true to her. She, like Carol and Zemi, is a female tracker. She had the same hot and arousing feelings for Carol and other such women that Maria had for Carol's lovely body, tits, and bums. When Cora arrived to meet Maria, the latter seemed to be in parts to uncover Carol's story of how she ran over her and how she put on something else and felt hot affections for Carol. On the other hand, Cora immediately became energized upon hearing the story and gave vent to her passionate desire to know every detail. Maria narrated the story like a hurried schoolchild who had just gotten the lustful feeling from seeing the trapping stuff. Cora also brought the organization together with the greatest of intrigue and wanted to be a part of the experience. She had to savour the taste of the prey.

"So what happened?" Cora asked in her most conspirational voice. Maria told what had happened."

Maria wanted to portray all of the finer details of the Cora's story in order to solicit the subtleties of the encounter. She recalled Carol's gathering and continued in the manner in which the warrior originates from his missions and says the moment subtleties of the experience and appreciates it all. During the talk, Maria revealed to Cora that she was in a hurry to keep her feelings. In the presence of Father Arroyo, she was unable to quench her thirst. Cora was softening in herself as the story progressed, and she became curious to learn more and practiced with Carol. Cora was enraged by Priest's obstinacy when she heard the sex requirement. She had a soft spot for her companion and she could not do something bad about Carol's tempting body. Carol appeared to be prey for them; they searched for her for a long time. Maria was invested in irritated emotions because she could not entice Carol's charming hot assemblage, so she would have no choice but to do nothing helpful. Father Arroyo annoyed her, and she began to cry for the first time in a long time.

Miriam, Maria's other companion, had a different take on Father Arroyo. She considers Father Arroyo to be a man of betrayal. He is not internally religious, but he is looking for an externally strict and devout man. She claims that he is a two-faced man who is deceiving people with his white shroud. His white shroud is not a picture of outstanding quality but rather a dark sheet from inside. The dim dark shading from within represents the thickness of extortion, exotic nature, and devious scheme for unadulterated women. He, she reasoned, would lure Carol, into vulgarity. Carol had only admired this type of misinterpretation that the Spanish were evil exploiters who exploited poor women as employees and had secret love-illicit relationships with the women who served them.

"I had heard all about Spanish priests who use young women as servants. They are a pathetic breed of men who hide behind their positions in the church to impress and use women."

Carol explores her short biopic with Miriam and Zemi and enlightens them about their parents' motherland, that her mother had a place with Toledo, Spain and that she was enthusiastically infatuated with her mother. In response to a question from Maria, she hesitantly said that she had developed a strong dislike for her father to the point where she did not even try to think about his roots. She included that,

"He gave his past to create a new one that makes absolutely no sense to who he was."

\section{Conclusion}

The research study was designed to discover Linguistic Taboos, investigate the impact of Linguistic Taboos on Carol, the protagonist, and highlight the effects of Linguistic Taboos on Spanish society in Ibis Gomez Vega's "Send My Roots Rain." According to Batistella, forbidden terms fall into four categories: epithets, profanity, vulgarity, and obscenity. The characters in the novel have used these forbidden words, which have a repulsive effect on the minds of the readers. Carol, the novel's protagonist, is spoiled by Spain's filthy environment. She travelled to a scorching desert to paint murals in a chapel. However, she cannot stop herself from becoming a lesbian there. Linguistic taboo words and phrases used during interactions drove her to act like a dirty girl around other people. Her coming out as a lesbian would not send a positive message to the rest of Spain or society in general. Since lesbianism is a taboo subject in and of itself. It was clear that there was a need for no-no laws; the rules unmistakably needed to interface culture to untouchable, emphasizing the importance of handling taboos within the system of the Interpreting Codes of Ethics. The rules should include preparation suggestions, such as bringing problems to light in light of the different types of taboo words. Preparation in perceiving forbidden terms and restricted body movements are also part of the law. The study looked for Linguistic Taboos in Ibis Gomez Vega's Send My Roots Rain. These linguistic taboos can reveal a woman's lust for the same sex. The two undercurrents in the story, Lesbianism demonstrations and the promotion of Lesbianism are indecent and contrary to strict and natural practices. In the public sphere, a survivor of this form of desire is insufficient. 


\section{References}

[1] Abi-Esber, F., Yang, P., Muranaka-Vuletich, H., \& Moustakim, M. (2018). Linguistic taboos: a case study on Australian Lebanese speakers. Asian Culture and History, 89-98.

[2] Ahmad, I. (2015). The Influence of Social Taboos on Socialization of Students. Mediterranean Journal of Social Sciences: Evidence from a Developing Country.

[3] Anggita, F. N. (2015). A Socio Linguistic Analysis of Taboo Words in Bad Language. Faculty of Languages and Arts YOGYAKARTA STATE UNIVERSITY, 97.

[4] Batistella, E. (2005). Bad Language: Are Some words Better Than the Others? Oxford Uninversit Press.

[5] Butler, J. (1990). Gender Trouble, Feminism and The Subebversion of Identity. (L. J. Nicholson, Ed.) New York, London: Ruthlege Chapman and Hall.

[6] Freud, S. (1913). Totem and Taboo: Resemblence between the Menatal lives of the Savages and Neurotics. Hogarth Press UK.

[7] Hornby, A. (2005). Learner's English Chinese Dictionary (6th ed.). Oxford University Press.

[8] Jing-Shmitd. (2019). Cursing, Taboo, and Euphemism. Retrieved from https://www.researchgate.net/publication/318042045

[9] Khaghaninejad, M. S. (2020). An Investigation into the Effect of Foreign Languagage Learning on the Use of Taboo Words in the Learners' First Language Discourse. English Teaching Language, Vol. 14, No. 1, Winter \& Spring 2020, pp. 91-117.

[10] Kurniawati, T. R. (2019). Taboo Words in the TV Series Stranger Things. LEXICON Volume 6, Number 1, April 2019, 87-97, 11.

[11] Niraulla, N. (2015). Linguistic Taboos and Eupheuisms in Nepali. Retrieved from https://en.wikipedia.org/wiki/Nepali_languag

[12]Richards, J. (2015). "Schitworde": Analysis of linguistic taboo in the history of the semantic field of excrement. Purdue University Purdue e-Pubs.

[13] Uhlman, k. (2015). Use and Perception of Taboo Language in College Age Females. University of New Hamshire Scholar's Repository.

[14] Vega, I. G. (1991). Send My Roots Rain (first Edition ed.). Aunt Lute Books.

[15] Walker, T. (2015). Accommodating Taboo Language in English Language Teaching: Issues of Appropriacy and Authenticity. ERIC Number: EJ1062204, 13 . 